\title{
Environmental Monitoring of the Coal Cluster in Transition to Sustainable Development
}

\author{
Eva Scherbenko, ${ }^{1,}$, Eyvaz Gasanov ${ }^{2}$, Maxim Tyulenev ${ }^{3}$, Sergey Kovalevsky ${ }^{3}$, Radim \\ Rybár $^{4}$, and Leonid Lopukhinsky ${ }^{5}$ \\ ${ }^{1}$ Siberian Federal University, 660075 Lida Prushinskaya St. 2, Krasnoyarsk, Russia \\ ${ }^{2}$ Khabarovsk State University of Economy and Law, 680042134 Tikhookeanskaya st., Khabarovsk, \\ Russia \\ ${ }^{3}$ T.F. Gorbachev Kuzbass State Technical University, 650000 Kemerovo, 28 Vesennya st., Russia \\ ${ }^{4}$ Technical University Košice, Faculty BERG, Letná 9, 04001 Košice, Slovakia \\ ${ }^{5}$ T.F. Gorbachev Kuzbass State Technical University, Mezhdurechensk Branch, 652881 \\ Mezhdurechensk, 36 Stroiteley st., Russia
}

\begin{abstract}
The transition to sustainable development implies the spread of new environmental management standards in all industrial sectors extractive, processing, high-tech, and infrastructure branches. This means that the industries traditionally engaged in the extraction of minerals (coal, ore, oil and gas, etc.) should take a direct part in the process of reducing land use, restoring disturbed landscapes and water bodies, reducing harmful emissions. At the same time, the mining complex is faced with the task of meeting the constantly growing needs of humanity for modern goods and services, the production of which, one way or another, requires an increase in the extraction of natural resources. In this regard, the article considers the monitoring of natural resources as a starting point for the transition of regional production systems to sustainable development. The study was based on the largest Russian coal cluster Kuzbass. The system for monitoring natural resources at the regional cluster level is considered.
\end{abstract}

\section{Introduction}

The impact of mining on the environment and natural resources is multifaceted, long-term and complex. The set of works on coal mining causes geomechanical, hydrological, chemical, physical-mechanical, thermal and biological changes in the environment.

Currently, the impact of mining on the environment has gone far beyond the mining (land) allotments of enterprises, which turns the local environmental problem of a coal mining or coal processing enterprise into a regional geoecological problem.

In this regard, it is of considerable interest to assess the impact on the environment not only of an individual mining facility, but also of the entire complex of mining industries located in a given area [1-2]. Achievement of this goal is ensured by a system of both ground and remote monitoring.

\footnotetext{
* Corresponding author: sherbenko.e@mail.ru
} 
The current monitoring system for the coal industry of Kuzbass (Western Siberia, Russia) as a whole practically does not use modern approaches to analyzing the state and determining the prospects for improving the natural environment [3]. It is aimed at controlling a number of ecological parameters of a point nature and does not allow for the provision of a spatial representation of the assessment and forecast of the geo-ecological state of coal-mining regions [4-5]. Let us consider some of the main issues of creating a new methodological apparatus for monitoring, assessing and forecasting the geo-ecological situation based on modern geo-information technologies and modeling tools.

\section{Materials and Methods}

A human being as a biological species can live comfortably only in a biological environment, therefore, one of the main principles of sustainable socio-economic development is the preservation of the natural human habitat and its restoration after destructive influences [67]. The stability of ecosystems depends on the diversity of the species included in them, on the ratio of the number of species occupying different ecological niches and trophic levels, on the reproductive properties of organisms and the regulation of the number by interspecific relationships in the community and abiotic factors [8-9]. Assessment of the quality of the natural environment is a key task of any activities in the field of ecology and rational nature management. Because of monitoring, two important results can be achieved - forecasting the state of ecosystems and regulating the quality of the environment through management [10$11]$.

The purpose of local monitoring is to objectively assess the state of the environment. Its tasks include the following:

- studying of the state of soil and vegetation cover, fauna;

- analyzing dynamics of environmental pollution;

- researching in dynamics of changes in climatic factors.

The systematic reflection of the elements of the environmental monitoring process is shown in Fig. 1.

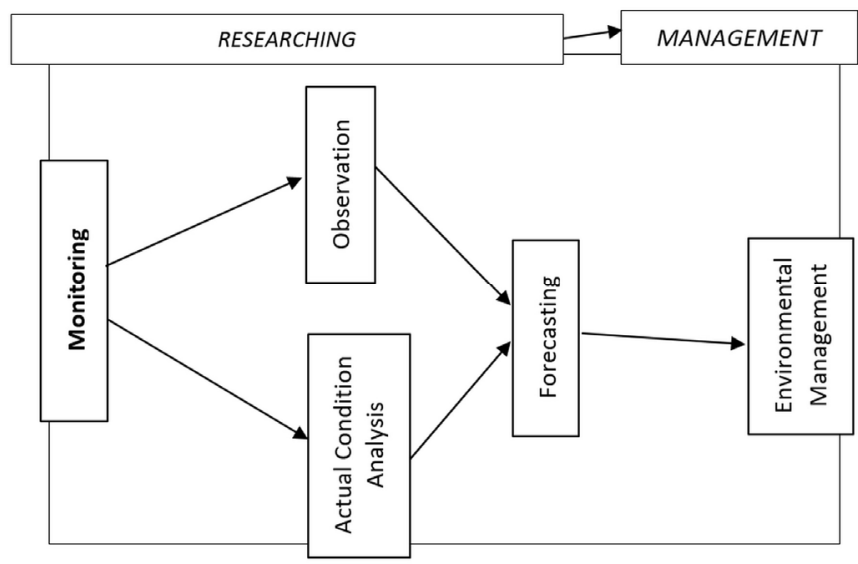

Fig. 1. Components of the monitoring process in the environmental management system.

The main element of the environmental monitoring system in the regional coal cluster is the impact zone of the technogenic objects. It is the territories around industrial enterprises, within which their influence on the environment is spread. This is reflected in the 
deterioration of the air, water and geological environment (pollution, imbalance of water, natural landscape distraction, etc.) [12].

The most important monitoring tasks are data collection, analysis and assessment of natural and fabricated changes in the state of the environment, identification of natural and man-made factors [13].

To solve these problems, a broad research program and modeling of changes in the state of the environment are required, namely:

- monitoring of the state of the environment, collection of data characterizing the reaction of environmental elements to any natural and man-made impacts;

- monitoring of technogenic factors affecting the climate and the state of the environment; monitoring the sources of these impacts;

- monitoring and modeling of physical and natural changes in the environment as a result of technogenic activities of industrial enterprises.

As applied to the coal cluster, the object-and-specific structure of monitoring its ecosystems includes direct (ground) and remote observation (Fig. 2).

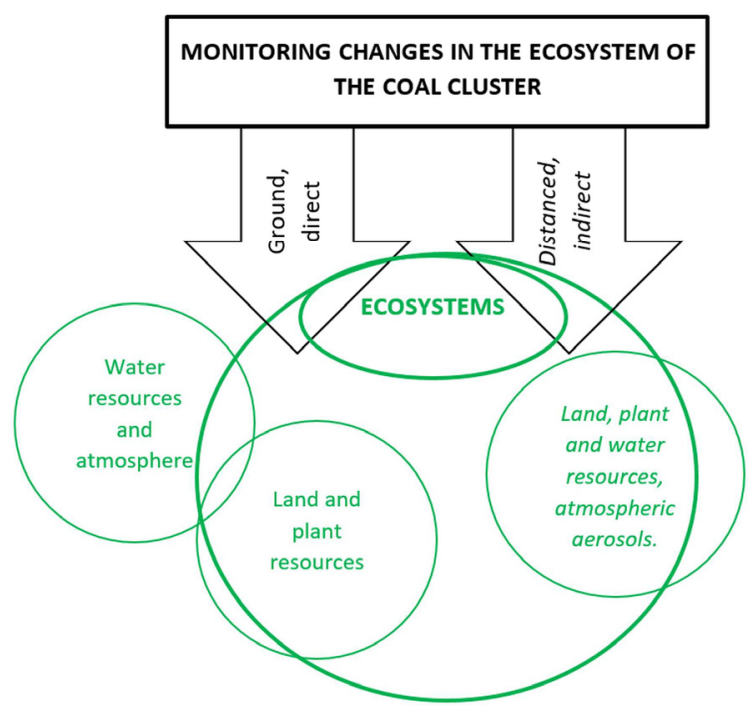

Fig. 2. Object-and-specific structure of monitoring the ecosystems of the coal cluster.

From the draft shown in Fig. 2, it follows that a comprehensive presentation of the environmental monitoring system of a coal mining cluster should include an overview of the state of various types of resources that form the ecosystem. At the same time, obtaining information about the state of the ecosystem can be carried out both from the territory of the cluster itself, as well as remotely (including data from satellites, drones, aerial photography) [14-15].

\section{Results and Discussion}

Modern natural environment monitoring system in the coal-mining region is an information and computing system, in which the accumulation and processing of data from both ground and remote-based sources takes place. In general, the modern monitoring system is a block structure (Fig. 3), linked by a single approach that integrates research using geographic 
information systems, remote sensing data and new methods of accumulation, processing and analysis of heterogeneous spatial data.

\begin{tabular}{|c|c|c|c|c|c|c|c|}
\hline \multirow{4}{*}{ 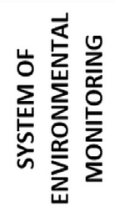 } & \multicolumn{7}{|c|}{ Admissibility of changes and loads on the environment } \\
\hline & \multicolumn{7}{|c|}{ Sources and factors of influence on the environment } \\
\hline & \multicolumn{7}{|c|}{ State of the environment } \\
\hline & \multicolumn{7}{|c|}{ Existing reserves of the environment } \\
\hline & \multicolumn{7}{|c|}{ ENVIRONMENTAL MONITORING PROCEDURES } \\
\hline & 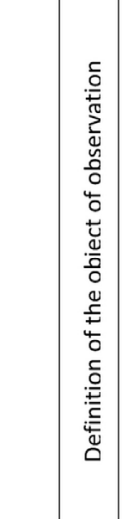 & 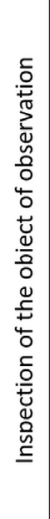 & 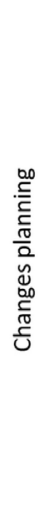 & 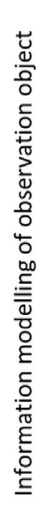 & 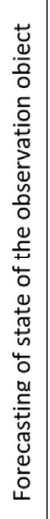 & 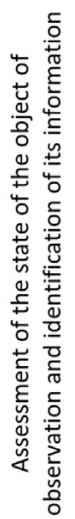 & 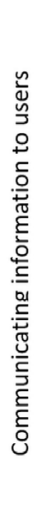 \\
\hline
\end{tabular}

Fig. 3. System for monitoring the environment of the mining area.

Distinctive feature of information support of modern environmental monitoring systems is their distribution. This ensures the placement of individual blocks of the system on the Internet with the organization of remote access based on typical client programs. This approach not only allows for the rapid development of environmental monitoring subsystems, but also makes it possible to expand them due to specific types of computing services determined by means of cloud technologies.

Thus, for comprehensive assessment of the quality of technogenic pollution of waters requires the use of a whole range of modern physicochemical methods and instruments (chromateaand-mass spectrometers, atomic emission spectrometers with inductively coupled plasma, spectrum analyzers of gamma radiation, etc.), which is necessary to identify specific pollutants in discharge of various industries enterprises and determination of their contributions to the general pollution of surface and deep waters.

The following groups of organic compounds are found in mine and quarry waters: aliphatic and aromatic hydrocarbons, PAHs, alcohols, carboxylic acids and their esters, phenols. The following organic substances are found in waste water from coke chemistry are benzopyrene, fluorene, phenanthrene, anthracene, fluoranthene, pyrene, methyl-, dimethyl-, trimethyl-substituted naphthalenes, phenols. All these pollutants are currently not included in any of the existing monitoring programs.

The technology for minerals extraction, in particular for coal by the surface way, presupposes the emergence of a large number of sources that affect the state of the environment. The main factors of influence are mining operations and technogenic land objects (quarries, dumps, technological routes, mining and processing enterprises, coal warehouses, etc.). The most common representatives of technogenic landscapes are dumps of overburden and enclosing rocks. They also have the most intensive impact on natural 
ecosystems. External dumps of overburden are occupied by a significant share of the land allotment of a mining enterprise (from 30 to $60 \%$ of the land allotment).

All these data are examples of the particular importance that the monitoring of the ecosystem of a coal-mining region is acquiring as a starting point for its transition to sustainable development.

\section{Conclusion}

The impact of man-made objects on the natural ecosystem at the initial time stage is hardly noticeable as a result of the elasticity and plasticity of natural complexes in relation to external anthropogenic factors. At the same time, the most important factors are manifested, which are capable of noticeably changing the natural characteristics of environment in a short time. Over time, the negative impact of coal mining on environment and its intensity increase, modifying the structural and functional features of the ecosystem or introducing significant deviations into it. Therefore, an integrated system for natural resources monitoring is needed, including both ground and remote monitoring. The system for monitoring natural resources is of particular importance in Kuzbass, in which enterprises engaged in mining and processing of coal have a complex effect on the ecosystem.

\section{References}

1. I. Kudryashova, M. Venger, N. Zakharova, E3S Web Conf. 105, 02005 (2019)

2. E. Shavina, V. Prokofev, E3S Web of Conferences, 174, 02014 (2020)

3. I. Kudryashova, N. Zakharova, E. Kharlampenkov, E3S Web Conf. 21, 02016 (2017)

4. M.S. Zlotnikov, V.V. Telnykh, S.I. Mutovin, S.K. Demchenko, J.J. Suslova, Journal of Environmental Management and Tourism, 8(2), 366-372 (2017)

5. S.K. Demchenko, J.J. Suslova, A.S. Yamschikov, I.R. Ruyga, T.A. Melnikova, Journal of Applied Economic Sciences 12(1), 194-205 (2017)

6. N.K. Sedykh, I.N. Tchaikovskaya, Economics and Innovation Management, 1, 74-83 (2021) DOI: 10.26730/2587-5574-2021-1-74-83

7. T.V. Kiseleva, V.G. Mikhailov, Ya.S. Mikhailova Economics and Innovation Management, 1, 63-73 (2021) DOI: 10.26730/2587-5574-2021-1-63-73

8. S. Zhironkin, M. Gasanov, G. Barysheva, E. Gasanov, O. Zhironkina, G. Kayachev, E3S Web Conf. 21, 04002 (2017)

9. M. Yazevich, O. Kalinina, O.Zhironkina, E3S Web Conf. 134, 03004 (2019)

10. S.M. Sukhorukova, A.M. Pogorely, A.V. Samorokov, Economics and Innovation Management, 1, 54-65 (2020) DOI: 10.26730/2587-5574-2020-1-54-65

11. E. Shavina, V. Prokofev, E3S Web Conf. 174, 04017 (2020)

12. M. Tyulenev, E. Garina, A. Khoreshok, O. Litvin, Y. Litvin, E. Maliukhina, IOP Conference Series: Earth and Environmental Science, 50(1), 012035 (2017)

13. E.Shavina, S. Fisunov, E3S Web Conf. 105, 04018 (2019)

14. Š. Kuzevič, Gergel’ová Bindzárová, Ž. Kuzevičová, V.G. Mikhailov, Economics and Innovation Management, 3, 9-20 (2020) DOI: 10.26730/2587-5574-2020-3-9-20

15. Z. Šimková, M. Cehlár, H. Pavolová, M.A. Tyulenev, Economics and Innovation Management, 3, 47-58 (2020) DOI: 10.26730/2587-5574-2020-3-47-58 